\title{
Oral dabigatran etexilate versus enoxaparin for venous thromboembolism prevention after total hip arthroplasty: pooled analysis of two phase 3 randomized trials
}

Bengt I. Eriksson ${ }^{1 *}$, Ola E. Dah2 ${ }^{2,3}$, Nadia Rosencher ${ }^{4}$, Andreas Clemens ${ }^{5,6}$, Stefan Hantel ${ }^{7}$, Martin Feuring ${ }^{5,8}$, Jörg Kreuzer ${ }^{5,8}$, Michael Huo ${ }^{9}$ and Richard J. Friedman ${ }^{10}$

\begin{abstract}
Background: Two phase 3 trials compared 28-35 days of treatment with oral dabigatran $220 \mathrm{mg}$ or $150 \mathrm{mg}$ (RE-NOVATE) or $220 \mathrm{mg}$ (RE-NOVATE II) once daily with subcutaneous enoxaparin $40 \mathrm{mg}$ once daily for prevention of venous thromboembolism (VTE) after elective total hip arthroplasty.

Methods: This prespecified pooled analysis compared the outcomes for the dabigatran $220 \mathrm{mg}$ dose with enoxaparin, which included 4,374 patients. Total VTE (venographic and symptomatic) plus all-cause mortality (primary efficacy), major VTE (proximal deep vein thrombosis [DVT] or non-fatal pulmonary embolism) plus VTE-related death, and bleeding events were evaluated. Efficacy analysis was based on the modified intention-to-treat (ITT) population and safety analysis was based on all treated patients. The common risk difference (RD) for dabigatran versus enoxaparin was estimated using a fixed effects model.

Results: Total VTE and all-cause mortality occurred in $6.8 \%(114 / 1,672)$ and $7.7 \%(129 / 1,682)$ (RD:-0.8 \%, $95 \%$ confidence interval [Cl] -2.6 to 0.9) for dabigatran and enoxaparin, respectively. Major VTE plus VTE-related mortality occurred in $2.7 \%(46 / 1,714)$ and $4.0 \%(69 / 1,711)$ (RD: $-1.4 \%, 95 \% \mathrm{Cl}-2.6$ to -0.2$)$ of patients receiving dabigatran $220 \mathrm{mg}$ and enoxaparin, respectively. Major bleeding occurred in $1.7 \%(37 / 2,156)$ and $1.3 \%(27 / 2,157)$ (RD: $0.5 \%$, $95 \% \mathrm{Cl}-0.2$ to 1.2$)$, for dabigatran and enoxaparin respectively.
\end{abstract}

Conclusions: Extended prophylaxis with oral dabigatran 220 mg once daily was as effective as enoxaparin 40 mg once daily in reducing the risk of total VTE and all-cause mortality after total hip arthroplasty, with a similar bleeding profile. The clinically relevant outcome of major VTE and VTE-related death was significantly reduced with dabigatran versus enoxaparin.

Trial registration: NCT00657150 and NCT00168818

Keywords: Arthroplasty, Bleeding, Enoxaparin, Dabigatran, Deep vein thrombosis, Mortality, Prophylaxis, Pulmonary embolism, Venous thromboembolism

\footnotetext{
* Correspondence: bengt.eriksson@gu.se

'Department of Orthopaedics, Sahlgrenska University Hospital, SE 41345 Gothenburg, Sweden

Full list of author information is available at the end of the article
}

\section{Biomed Central}

(c) 2015 Eriksson et al. Open Access This article is distributed under the terms of the Creative Commons Attribution 4.0 International License (http://creativecommons.org/licenses/by/4.0/), which permits unrestricted use, distribution, and reproduction in any medium, provided you give appropriate credit to the original author(s) and the source, provide a link to the Creative Commons license, and indicate if changes were made. The Creative Commons Public Domain Dedication waiver (http://creativecommons.org/publicdomain/zero/1.0/) applies to the data made available in this article, unless otherwise stated. 


\section{Background}

Dabigatran etexilate (hereafter referred to as dabigatran) is an orally administered direct, reversible thrombin inhibitor for the prevention and treatment of various thromboembolic disorders. Two previously reported phase 3 trials (RE-NOVATE and RE-NOVATE II) $[1,2]$ compared the efficacy and safety of dabigatran $(220 \mathrm{mg}$ or $150 \mathrm{mg}$ once daily, started $1-4 \mathrm{~h}$ after surgery) with enoxaparin (40 mg once daily, started at least $12 \mathrm{~h}$ before surgery) for the prevention of venous thromboembolism (VTE) and all-cause mortality after elective total hip arthroplasty. In both of these studies, the noninferiority of dabigatran $220 \mathrm{mg}$ over enoxaparin $40 \mathrm{mg}$ for the primary efficacy endpoint, total VTE (the composite of symptomatic and asymptomatic venographic deep vein thrombosis [DVT], non-fatal pulmonary embolism [PE]) plus all-cause mortality, was demonstrated. Bleeding and adverse event (AE) rates with dabigatran were low and similar to those reported for enoxaparin. Dabigatran $220 \mathrm{mg}$ once daily (starting with a half dose $1-4 \mathrm{~h}$ after the end of surgery) is now approved in more than 100 countries for thromboprophylaxis in patients undergoing total hip arthroplasty.

The prespecified pooled analysis of these two studies was planned to compare the effect of dabigatran $220 \mathrm{mg}$ and enoxaparin $40 \mathrm{mg}$ once daily on the primary efficacy endpoint of total VTE and all-cause mortality in patients undergoing total hip arthroplasty.

\section{Methods}

\section{Study design and setting}

RE-NOVATE and RE-NOVATE II were prospective, double-blind, double-dummy, randomized, multicentre, non-inferiority studies.

Participants were adults aged at least 18 years who were scheduled for primary elective total hip arthroplasty. The two trials had identical study eligibility criteria and were designed to be as similar as possible. Briefly, patients were randomized to treatment with oral dabigatran $220 \mathrm{mg}$ or $150 \mathrm{mg}$ once daily (the latter dose was not used in RE-NOVATE II), or subcutaneous enoxaparin $40 \mathrm{mg}$ once daily started the evening before surgery; in some countries enoxaparin treatment was started postoperatively in accordance with local practice.

The first dose of dabigatran was halved and given 1-4 $\mathrm{h}$ after wound closure, provided clinical assessment of perioperative and postoperative bleeding and drainage indicated adequate hemostasis. If administration was delayed until the day after surgery, a full dose was given, followed by a second dose at least $12 \mathrm{~h}$ later. Treatment was continued until mandatory bilateral venography at 28-35 days. In both trials, the treatment period was defined as the time from first dose to 3 days after the last dose. Continued VTE prophylaxis was at the discretion of the treating physician. Patients attended a clinical follow-up visit 3 months after surgery. Concomitant administration of low dose aspirin (<160 mg) and selective cycloxygenase-2 inhibitors was allowed during treatment. Elastic compression stockings were permitted, but intermittent pneumatic compression devices were prohibited.

Both studies were approved by National Independent Ethics Committees and conducted according to the Declaration of Helsinki (October 1996 version). All patients gave signed informed consent prior to entry.

\section{Outcome measures}

The prespecified primary efficacy endpoint of this pooled analysis was identical with that of the individual trials, i.e., the composite of total VTE and all-cause mortality. The endpoint was analyzed in the modified intention-to-treat (mITT) population, comprising all randomized and treated patients who underwent elective total hip arthroplasty and had evaluable adjudicated data on VTE (venographic confirmation in both legs or symptomatic event) or died during the treatment period. The main secondary efficacy outcome was the composite of major VTE (venographic or symptomatic proximal DVT and/or PE) and VTE-related mortality during treatment. Additional predefined secondary efficacy outcomes during the treatment period included total DVT (venographic or symptomatic), proximal DVT (venographic or symptomatic), and symptomatic DVT and/or PE.

All efficacy endpoints were based on assessments made by the same blinded Independent Venous Thromboembolic Event Adjudication Committee. Mandatory bilateral venography was performed within $24 \mathrm{~h}$ of the last oral dose, as described previously [3]. Suspected symptomatic DVT during treatment or follow-up was confirmed by ultrasound or venography. Symptoms suggestive of PE mandated confirmation by ventilation-perfusion scintigraphy, pulmonary angiography or spiral chest computer tomography, depending on local center preference. Deaths were considered related to VTE if they were categorized as "VTE related" or "unexplained" by the Independent Adjudication Committee.

All randomized patients who received at least one dose of study treatment were evaluable for safety. The main safety endpoint was the frequency of major bleeding events (which, different to previously performed studies, also included bleeding from the surgery wound site) occurring between intake of the first dose of study medication and 3 days after the last dose. Secondary safety outcomes included the composite of major and clinically relevant non-major bleeding events, any bleeding events during treatment, liver enzyme elevations $(\geq 3 \mathrm{x}$ the upper limit of the normal reference range (ULN) for serum alanine aminotransferase [ALT]) and acute 
coronary events (defined as confirmed unstable angina, myocardial infarction [MI], and cardiac death). This is in line with a number of pooled analyses from total knee and hip replacement trials with dabigatran, which included more than 8,000 patients $[4,5]$. Major, clinically relevant, non-major and minor bleeding events were defined according to accepted guidelines [6], as reported previously [3]. In particular, the definition of major bleeding includes wound site bleeding events, in accordance with recommended guidelines [6]. ALT elevations $\geq 3 \times$ ULN and any suspected acute coronary syndrome events were reviewed by an Independent Committee who were blinded to treatment allocation. An assessment of causality was provided for each of the reviewed patient cases.

\section{Statistical analysis}

The statistical analysis plan described here was planned before commencement of the RE-NOVATE II trial in accordance with regulatory recommendations [7].

For each trial, the difference in the proportion of patients with an event (efficacy or safety) was compared between dabigatran $220 \mathrm{mg}$ and enoxaparin $40 \mathrm{mg}$ as a risk difference (RD) as this was considered the most clinically meaningful measure. A common RD estimate across the two trials was calculated using a fixed-effects model (maximum likelihood estimation) [8], based on inverse variance weights for combined results from the individual trials, and compared with results obtained with a random effects model (DerSimonian and Laird method). The RD was not expected to differ between

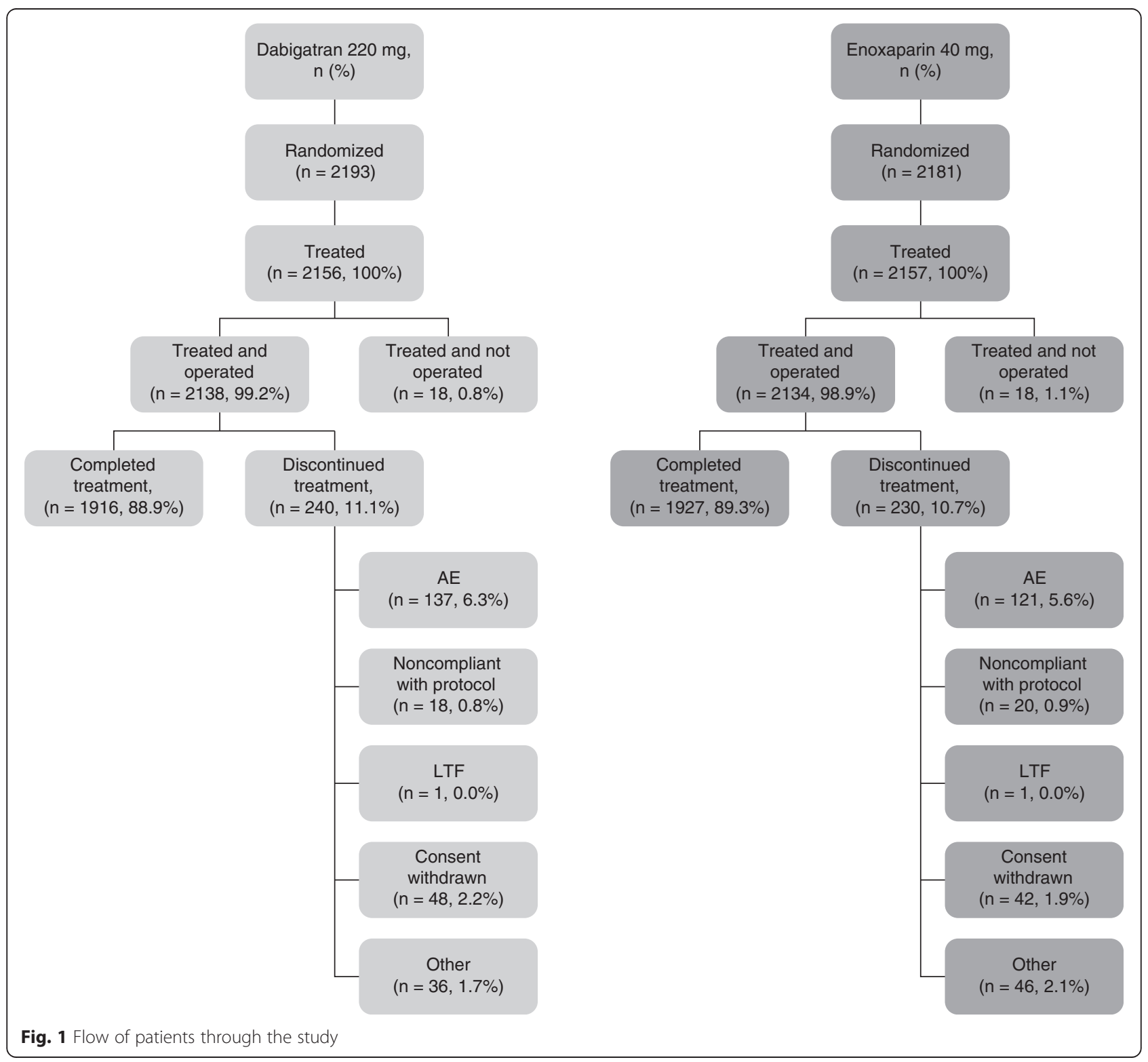


the studies. Heterogeneity of the common RD between the studies was assessed using Cochran's $X^{2}$ and the $I^{2}$ statistic; $\mathrm{p}<0.10$ was considered to denote statistically significant heterogeneity and where $\mathrm{I}^{2}$ was greater than $50 \%$, heterogeneity was considered substantial [9]. Pooled event rate data for each treatment group are presented alongside the common RD results obtained from the pooled analysis.

Subgroup analyses were planned to investigate the influence of age, body weight, gender, and renal function (determined from calculated baseline creatinine clearance) on the incidence of the primary efficacy outcome, as well as bleeding events. For these comparisons the odds ratio and $95 \%$ confidence intervals (CIs) for the analyzed subgroups were calculated using a fixed-effects model for the efficacy and safety endpoints.

Sensitivity analyses were conducted to explore the robustness of the results. The impact of missing or nonevaluable venography data, based on imputation of missing values using best and worst case scenarios (all treatment success or all treatment failure), was investigated to ensure that missing data did not affect the

Table 1 Demographic and baseline characteristics

\begin{tabular}{|c|c|c|}
\hline & $\begin{array}{l}\text { Dabigatran } 220 \mathrm{mg} \\
(n=2,156)\end{array}$ & $\begin{array}{l}\text { Enoxaparin } 40 \mathrm{mg} \\
(n=2,157)\end{array}$ \\
\hline Number of treated patients & 2,156 & 2,157 \\
\hline Age, yr & $63 \pm 11$ & $63 \pm 11$ \\
\hline Females, $n(\%)$ & $1177(54.6)$ & $1152(53.4)$ \\
\hline Weight, kg & $79 \pm 16$ & $79 \pm 16$ \\
\hline Body mass index ${ }^{a}$ & $27.8 \pm 4.7$ & $27.6 \pm 4.6$ \\
\hline Previous VTE, n (\%) & $65(3.0)$ & $54(2.5)$ \\
\hline Creatinine clearance ${ }^{\mathrm{b}}, \mathrm{mL} / \mathrm{min}$ & $92 \pm 31$ & $93 \pm 31$ \\
\hline \multicolumn{3}{|l|}{ Race $^{c}, n(\%)$} \\
\hline White & $2,051(95.1)$ & $2,052(95.1)$ \\
\hline Asian & $96(4.4)$ & $88(4.1)$ \\
\hline Black & $5(0.2)$ & $12(0.6)$ \\
\hline Other & $4(0.2)$ & $5(0.2)$ \\
\hline \multicolumn{3}{|l|}{ Geographical region, n (\%) } \\
\hline Western Europe & $1,282(59.5)$ & $1,291(59.9)$ \\
\hline Central Europe & $474(22.0)$ & $470(21.8)$ \\
\hline North America & $170(7.9)$ & $168(7.8)$ \\
\hline India & $91(9.0)$ & $88(4.1)$ \\
\hline Australia/New Zealand/South Africa & $139(6.4)$ & $140(6.5)$ \\
\hline Patients treated and operated, $n(\%)$ & $2,138(99.2)$ & $2,134(98.9)$ \\
\hline \multicolumn{3}{|l|}{ Anesthesia $^{d}, n(\%)$} \\
\hline General alone & $525(24.4)$ & $503(22.3)$ \\
\hline Neuraxial alone $e^{e}$ & $1,461(67.8)$ & $1,486(65.8)$ \\
\hline Combination $^{f}$ & $149(6.9)$ & $144(6.4)$ \\
\hline Mean duration of surgery $\pm S D$, min & $85.4 \pm 30.2$ & 85. \pm 30.4 \\
\hline \multicolumn{3}{|l|}{ Study treatment } \\
\hline Mean time to first subcutaneous injection ${ }^{g, h}$ in relation to surgery, $\mathrm{hr}$ & $-15.6 \pm 20.7$ & $-15.2 \pm 13.5$ \\
\hline Mean time to first oral dose postsurgery ${ }^{\mathrm{h}}, \mathrm{hr}$ & $3.1 \pm 2.6$ & $3.2 \pm 2.7^{9}$ \\
\hline Median (range) duration of hospital stay', d & $8.5(3-51)$ & $8.5(3-26)$ \\
\hline Median (range) treatment duration, $\mathrm{d}$ & $31.6(1-89)$ & $31.7(1-49)$ \\
\hline
\end{tabular}

Data are given as mean \pm SD except where indicated

$S D$ standard deviation, VTE Venous thromboembolism

${ }^{\mathrm{a} B o d y}$ mass index was defined as weight in kilograms divided by square of height in meters; ${ }^{\mathrm{b}} \mathrm{Creatinine}$ clearance rates were calculated using the

Cockcroft-Gault formula; ' As reported by the investigator; ${ }^{\mathrm{d} P a t i e n t s ~ m a y ~ h a v e ~ h a d ~ m o r e ~ t h a n ~ o n e ~ t y p e ~ o f ~ a n e s t h e t i c ; ~}{ }^{\mathrm{e}}$ Includes spinal and epidural anesthesia; ${ }^{f}$ Peripheral nerve block plus general or neuraxial anesthesia; ${ }^{g} 26$ patients in RE-NOVATE II group received their first dose postsurgery; ${ }^{h}$ Includes both active treatment and placebo; 'Time from surgery until day of discharge, data available in RE-NOVATE for 1,136 and 1,140 patients, respectively 
power of the trial or bias any estimation of the treatment effect.

\section{Results}

\section{Study population}

A total of 4,374 patients were randomized across 20 countries between December 2004 and May 2009, of whom 4,313 were treated and therefore evaluable for safety. 4,272 patients were operated upon and treated with oral dabigatran $220 \mathrm{mg}(n=2,138)$ or subcutaneous enoxaparin $40 \mathrm{mg}(n=2,134)$ (Fig. 1). A further 918 $(21.5 \%)$ patients were excluded from the mITT population, as usual in all studies with venography, mainly because bilateral venography was not performed (usually declined by the patient) or the venograms were considered indeterminate by the venography adjudication committee. This percentage is consistent with that reported in contemporary studies using venography as an endpoint $[3,10,11]$. In total, $240(11.2 \%)$ patients allocated dabigatran and 230 (10.7 \%) allocated enoxaparin discontinued treatment. The primary reasons for discontinuation were similar between groups. The two groups were well balanced in terms of demographic and surgical characteristics (Table 1).

\section{Efficacy outcomes}

Efficacy outcomes are summarized in Table 2. The primary outcome (the composite of total VTE and all-cause mortality) occurred in 114 (6.8 \%) patients treated with dabigatran $220 \mathrm{mg}$ and $129(7.7 \%)$ treated with enoxaparin $40 \mathrm{mg}$ (RD: $-0.8 \%, 95 \% \mathrm{CI}-2.6$ to $0.9 ; p=0.35$ ). Distal (below knee) DVT detected by venography was the most frequent component of the primary endpoint. There were four deaths during treatment; three in the dabigatran group (one related to VTE), and one in the enoxaparin group not related to VTE.

The main secondary outcome (composite of major VTE and VTE-related mortality) occurred in $2.7 \%$ with dabigatran versus $4.0 \%$ with enoxaparin (RD: $-1.4 \%$, $95 \%$ CI -2.6 to $-0.2 ; p=0.03)$. Symptomatic DVT occurred in $0.3 \%$ versus $0.2 \%(p=1.00)$, respectively. Over the whole 3-month (treatment plus follow-up) study period the rate of symptomatic VTE plus all-cause mortality was $0.9 \%$ in each treatment group.

There was a significant difference in the risk for proximal DVT (venographic or symptomatic) for dabigatran versus enoxaparin (RD: $-1.4 \%, 95 \% \mathrm{CI}-2.6$ to -0.3 ; $p=0.02$ ). No difference in total DVT (venographic or symptomatic) (RD: $-1.1 \%, 95 \% \mathrm{CI}-2.7$ to $0.6 ; p=0.22$ ) was observed. The incidence of symptomatic DVT and

Table 2 Efficacy outcomes, modified ITT population. Data are given as n/N (\%)

\begin{tabular}{|c|c|c|c|c|}
\hline Outcome & Dabigatran $220 \mathrm{mg}$ & Enoxaparin $40 \mathrm{mg}$ & Risk difference vs. enoxaparin, \% $(95 \% \mathrm{Cl})^{\mathrm{a}}$ & $\mathrm{p}$ value \\
\hline \multicolumn{5}{|l|}{ Total VTE and all-cause mortality } \\
\hline Pooled data & $114 / 1,672(6.8)$ & $129 / 1,683(7.7)$ & $-0.8(-2.6,0.9)$ & \multirow[t]{3}{*}{0.35} \\
\hline RE-NOVATE & $53 / 880(6.0)$ & $60 / 897(6.7)$ & $-0.7(-2.9,1.6)$ & \\
\hline RE-NOVATE ॥ & $61 / 792(7.7)$ & 69/786 (8.8) & $-1.1(-3.8,1.6)$ & \\
\hline \multicolumn{5}{|l|}{ Major VTE ${ }^{b}$ and VTE-related mortality ${ }^{c}$} \\
\hline Pooled data & $46 / 1,714(2.7)$ & $69 / 1,712(4.0)$ & $-1.4(-2.6,-0.2)$ & \multirow[t]{3}{*}{0.03} \\
\hline RE-NOVATE & $28 / 909(3.1)$ & $36 / 917(3.9)$ & $-0.8(-2.5,0.8)$ & \\
\hline RE-NOVATE ॥ & $18 / 805(2.2)$ & $33 / 795(4.2)$ & $-1.9(-3.6,-0.2)$ & \\
\hline \multicolumn{5}{|l|}{ Symptomatic events } \\
\hline Symptomatic VTE & $17 / 2,138(0.8)$ & $16 / 2,134(0.7)$ & & \\
\hline Symptomatic DVT & $6 / 2,138(0.3)$ & $5 / 2,134(0.2)$ & & 1.00 \\
\hline Symptomatic PE & $6 / 2,138(0.3)$ & $5 / 2,134(0.2)$ & & 1.00 \\
\hline Death & $3 / 2,138(0.1)$ & $1 / 2,134(0.0)$ & & 0.62 \\
\hline Total asymptomatic DVT & $100 / 1,665(6.0)$ & $122 / 1,677(7.3)$ & & \\
\hline Proximal & $35 / 1,709(2.0)$ & $63 / 1,706(3.7)$ & & \\
\hline Distal only & $65 / 1,666(3.9)$ & $59 / 1,679(3.5)$ & & \\
\hline \multicolumn{5}{|l|}{ Total study period (treatment + follow-up) } \\
\hline Symptomatic VTE + all-cause mortality & $18 / 2,048(0.9)$ & 19/2,059 (0.9) & & 0.09 \\
\hline
\end{tabular}


PE during treatment was comparable across treatments $(p=1.0)$ (Table 2). Similar results were reported for the main secondary outcome.

Bleeding-related outcomes are summarized in Table 3. There was no difference in major bleeding rates between the two groups; 37 (1.7\%) with dabigatran versus 27 (1.3\%) with enoxaparin (RD: $0.5 \%, 95 \% \mathrm{CI}-0.2$ to 1.2 ; $p=0.19$ ). Only one fatal bleeding event in the dabigatran group was reported. Of the 37 major bleeding events with dabigatran, 19 (51.4\%) occurred before any active study drug had been administered. In contrast, all bleeding events in the enoxaparin group occurred after the first dose, which was given preoperatively in $94 \%$ of patients. Similarly, there was no difference between the groups in the rate of major or non-major clinically relevant bleeding events (5.0\% versus $4.0 \%$ dabigatran and enoxaparin, respectively, $p=0.13$ ), overall bleeding rates or the requirement for blood transfusion.

\section{Subgroup analyses}

Treatment with dabigatran resulted in consistent reductions in the primary outcome irrespective of age $(<65$, $65-75,>75$ years, $p=0.05)$, weight $(\leq 70,>70-90,>90 \mathrm{~kg})$ $(p=0.50)$, gender $(p=0.54)$ or renal function (calculated creatinine clearance $>80,50-80,<50 \mathrm{~mL} / \mathrm{min}$ at baseline, $p=0.32$ ). There were no differences in the primary outcome across additional subgroups according to treatment (Fig. 2).

The results remained robust in sensitivity analyses (data not shown), indicating that missing venography data did not bias any estimation of the treatment effect. There were no differences between results obtained using the fixed versus random effects model.

\section{Adverse events}

The AE profile of each treatment was similar (Table 4). Postoperative wound infection was reported as an AE in 37 patients, $16(0.7 \%)$ in the dabigatran group and 21 $(1.0 \%)$ in the enoxaparin group. AEs leading to treatment discontinuation occurred in $6.2 \%$ and $5.5 \%$ of the dabigatran and enoxaparin groups, respectively (Table 4). Less than $1 \%$ of patients in either group had an adjudicated MI or ischemic stroke during or after treatment. Fifteen patients (8 [0.4\%] in the dabigatran group and 7 [0.3\%] in the enoxaparin group) had cardiovascular events (defined as ischemic stroke or MI) after $>3$ days off study drug.

Moderate liver enzyme elevation (ALT levels $>3 \mathrm{x}$ ULN) at any time after baseline occurred in $3.4 \%$ of the dabigatran group and $5.5 \%$ of the enoxaparin group (Table 4). In three patients in the dabigatran group, there was an associated two-fold increase in bilirubin

Table 3 Bleeding-related outcomes, safety population

\begin{tabular}{|c|c|c|c|c|}
\hline Outcome & $\begin{array}{l}\text { Dabigatran } 220 \mathrm{mg} \\
(n=2,156)\end{array}$ & $\begin{array}{l}\text { Enoxaparin } \\
(n=2,157)\end{array}$ & $\begin{array}{l}\text { Risk difference vs. enoxaparin, \% } \\
(95 \% \mathrm{Cl})\end{array}$ & $p$ value \\
\hline \multicolumn{5}{|l|}{ Bleeding Events } \\
\hline Major, Total no. patients, \% (95 \% Cl) $)^{a}$ & $37(1.7,1.2-2.4 \%)$ & $27(1.3,0.8-1.8 \%)$ & $0.5 \%(-0.2,1.2)$ & 0.20 \\
\hline Fatal & $1(0.05)$ & $0(0)$ & & \\
\hline In a critical organ & $2(0.1)$ & $0(0)$ & & \\
\hline $\begin{array}{l}\text { Clinically overt associated with } 20 \mathrm{~g} / \mathrm{L} \text { or more fall in } \\
\text { hemoglobin }\end{array}$ & $31(1.4)$ & $19(0.9)$ & & \\
\hline $\begin{array}{l}\text { Clinically overt leading to transfusion of two or more } \\
\text { units of packed cells or whole blood }\end{array}$ & $33(1.5)$ & $22(1.0)$ & & \\
\hline Warranting treatment cessation & $1(0.05)$ & $1(0.05)$ & & \\
\hline Leading to re-operation & $2(0.1)$ & $3(0.1)$ & & \\
\hline \multicolumn{5}{|l|}{ Onset of events - No. events/total no. patients (\%) } \\
\hline -Before the first oral dose & $19 / 37(51.4)$ & $10 / 28(35.7)$ & & \\
\hline -After the first oral dose & 18/37 (48.6) & $18 / 28(64.3)$ & & \\
\hline Clinically relevant non-major bleeding & $71(3.3)$ & $60(2.8)$ & & \\
\hline Major or clinically relevant non-major bleeding & $108(5.0)$ & $87(4.0)$ & $1.0 \%(-0.3,2.2)$ & 0.13 \\
\hline Minor bleeding & $131(6.1)$ & $128(5.9)$ & & \\
\hline Any bleeding events & $239(11.1)$ & $215(10.0)$ & & \\
\hline Patients receiving blood transfusions - n/N (\%) & $858 / 2,138(40.1)$ & $880 / 2,134(41.2)$ & & \\
\hline
\end{tabular}

Data are given as number (\%) of patients except where indicated

$\mathrm{Cl}$ confidence interval

${ }^{\text {a }}$ Patients may have been included in more than one category 


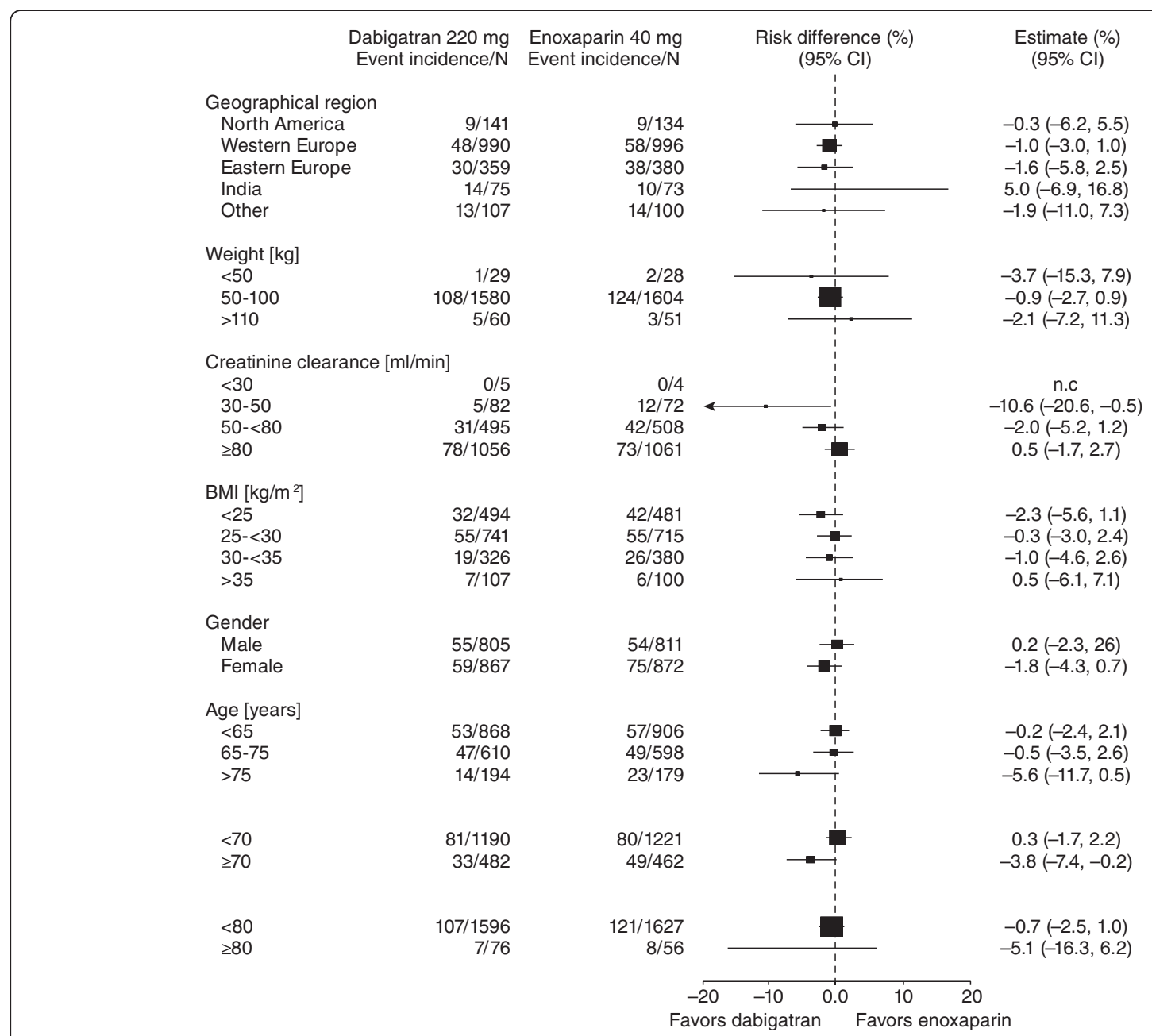

Fig. 2 Total VTE and all-cause mortality during treatment period by subgroup (risk differences)

elevation. None of these cases met the criteria (Hy's law) for severe drug-induced hepatotoxicity [12].

\section{Discussion}

The prespecified pooled analysis of these two studies was planned to compare the effect of dabigatran $220 \mathrm{mg}$ and enoxaparin $40 \mathrm{mg}$ once daily on the primary efficacy endpoint of total VTE and all-cause mortality in patients undergoing total hip arthroplasty. This pooled analysis of data from $\sim 4,300$ patients undergoing elective total hip arthroplasty in the two RE-NOVATE studies adds to the evidence base for dabigatran for prevention of thromboembolic complications.

Dabigatran $220 \mathrm{mg}$ was as effective as enoxaparin $40 \mathrm{mg}$ in decreasing the risk of VTE and all-cause mortality at 5 weeks. These results were consistent across age, weight, gender, or creatinine clearance subgroups. It is notable that the rate of major VTE and VTE-related death was significantly lower with dabigatran $(p=0.03)$, with a $1.4 \%$ absolute reduction in risk versus enoxaparin. This rate compares with the absolute reduction (0.7 to $1.7 \%)$ observed in studies with the oral FXa inhibitors (apixaban and rivaroxaban) versus enoxaparin in patients undergoing hip arthroplasty and receiving prophylaxis for an equivalent extended duration $[10,11]$. Thus, dabigatran may have similar benefits in reducing more clinically relevant, proximally located lower limb thrombi as other available oral anticoagulants.

The risk of bleeding was similar to that for enoxaparin. Bleeding rates (major, clinically relevant non-major, and minor bleeding) did not differ statistically between dabigatran and enoxaparin across the two studies. All but $33 \%$ of the major bleeding events were reported to have occurred after day 3, although the onset of bleeding could have started earlier.

Taken together, these results indicate that dabigatran is a useful prophylactic therapy in this clinical setting. By pooling the data from the two studies, a higher grade of 
Table 4 Adverse events, safety population

\begin{tabular}{|c|c|c|}
\hline \multirow[t]{2}{*}{ Outcome } & $\begin{array}{l}\text { Dabigatran } \\
220 \mathrm{mg}\end{array}$ & $\begin{array}{l}\text { Enoxaparin } \\
40 \mathrm{mg}\end{array}$ \\
\hline & $\begin{array}{l}(n=2,156) \\
n(\%)\end{array}$ & $\begin{array}{l}(n=2,157) \\
n(\%)\end{array}$ \\
\hline \multicolumn{3}{|l|}{ AEs during treatment } \\
\hline Total with AEs & $1,563(72.5)$ & $1,588(73.6)$ \\
\hline Serious AEs & $146(6.8)$ & $141(6.5)$ \\
\hline $\begin{array}{l}\text { AEs leading to treatment } \\
\text { discontinuation }\end{array}$ & $134(6.2)$ & $118(5.5)$ \\
\hline $\begin{array}{l}\text { Drug-related AEs (investigator } \\
\text { evaluation) }\end{array}$ & $191(8.9)$ & $199(9.2)$ \\
\hline Wound infections ${ }^{a}$ & $16(0.7)$ & $21(1.0)$ \\
\hline \multicolumn{3}{|l|}{ Cardiovascular events } \\
\hline Myocardial infarction & $2(<0.1)^{b}$ & $6(0.3)$ \\
\hline Ischemic stroke & 0 & $1(0.1)$ \\
\hline \multicolumn{3}{|l|}{ ALT elevation; no. (\%) patients } \\
\hline$>3 \times$ ULN anytime post baseline & $71 / 2,101(3.4)^{c}$ & $115 / 2,097(5.5)^{c}$ \\
\hline $\begin{array}{l}>3 \times \text { ULN plus bilirubin }>2 \times \text { ULN } \\
\text { during treatment period }\end{array}$ & $3 / 2,092(0.1)^{d}$ & 0/2,096 \\
\hline
\end{tabular}

Data are given as number (\%) of patients except where indicated $A E$ adverse event, $A L T$ alanine aminotransferase, ULN upper limit of normal ancludes wound hematomas, wound secretions, wound drainage and wound hemorrhage; ${ }^{b} \mathrm{~A}$ further event in RE-NOVATE II occurred in the follow-up period; 'Number of patients with abnormality/total number of patients having tests; ${ }^{\mathrm{d}} \mathrm{A}$ further patient in RE-NOVATE II had an elevation 3 months postsurgery while still in the follow-up period. None of the patients met the criteria for severe drug-induced hepatotoxicity [12]. One of these patients was diagnosed with acute cholangitis but a definitive diagnosis was not made in the other patient

power and prediction was achieved and allowed for an improved understanding. Specifically, the rarer, but clinically more relevant outcomes (major VTE and VTE-related mortality, or proximal VTE) regarding the performance of the oral anticoagulant dabigatran in comparison to subcutaneous enoxaparin could be investigated. Sensitivity analysis also demonstrated that missing data did not affect the power of the trial or bias any estimation of the treatment effect.

Other important outcomes included treatment-related wound complications and postoperative wound infections, all of which occurred with a similar frequency in each group. Such complications are clinically relevant, since bleeding assessment and wound-related AEs can affect surgical outcome and influence decisions regarding the provision of extended out-of-hospital prophylaxis. The AE profile, including liver enzyme elevations and cardiovascular events, was similar between dabigatran and enoxaparin.

Dabigatran is administered orally and is therefore more convenient than parenterally administered anticoagulants such as enoxaparin, particularly for out-of hospital prophylaxis. This is of relevance when considering current practice in the use of VTE prophylaxis. Despite guidelines recommending use of prophylaxis for up to 35 days after hip arthroplasty [13], compliance may be less than ideal. In one report, only $\sim 75 \%$ of patients treated with parenteral low-molecular weight heparin (e.g., enoxaparin) in hospital continued to receive it after discharge [14]. It is anticipated that these practical advantages are likely to confer cost advantages, supported by recent analysis. Indeed, economic evaluation, from the perspective of the UK National Health System, showed that extended prophylaxis with dabigatran was cost-effective compared with enoxaparin, given the substantial reduction in costs due to oral administration (pre- and postdischarge from hospital) [15]. Similar savings have been reported in other country-specific analyses from the healthcare system perspective $[16,17]$.

\section{Conclusions}

In conclusion, this pooled analysis of two trials comparing dabigatran with enoxaparin demonstrated that dabigatran was comparable to enoxaparin in preventing total VTE and all-cause mortality when used for the same duration, with a similar risk of bleeding and AEs. In clinical practice, dabigatran can be considered an attractive thromboprophylaxis in patients undergoing elective hip arthroplasty, with potential economic advantages.

\section{Abbreviations}

ALT: alanine aminotransferase; Cl: confidence interval; DVT: deep vein thrombosis; ITT: intention-to-treat; Ml: myocardial infarction; mITT: modified intention-to-treat; PE: pulmonary embolism; RD: risk difference; ULN: upper limit of the normal reference range; VTE: venous thromboembolism.

\section{Competing interests}

Bengt I Eriksson has received fees as a consultant or speaker for Astellas, Bayer, Boehringer Ingelheim, Daiichi Sankyo and Takeda. Nadia Rosencher has received fees as consultant or speaker for Aspen, Bayer, Bristol-Myers Squibb, GlaxoSmithKline, Pfizer, Boehringer Ingelheim and Sanofi. Ola E Dahl has been a scientific consultant for AstraZeneca, Bayer, Boehringer Ingelheim, Bristol-Myers Squibb, GlaxoSmithKline and Sanofi-Aventis. Richard J Friedman has received fees as a consultant for Johnson \& Johnson, Astellas and Boehringer Ingelheim, has received research grants from Astellas and Boehringer Ingelheim, and is on the speaker's bureau for Sanofi-Aventis. Michael $\mathrm{H}$ Huo has received fees as a consultant for Biomet, DePuy, Koycera, Pfizer, Janssen, AO Foundation and Zimmer. Andreas Clemens was an employee of Boehringer Ingelheim and is a current employee at Novartis Pharma. Stefan Hantel, Jörg Kreuzer and Martin Feuring are employees of Boehringer Ingelheim.

\section{Authors' contributions}

All authors were involved in the study design and/or the collection, analysis and interpretation of data, in writing the report, and the decision to submit for publication. All authors read and approved the final manuscript.

\section{Acknowledgements}

All trials were sponsored by Boehringer Ingelheim (BI). This work was supported by BI. The authors received no compensation related to the development of the manuscript. Dr. Vanessa Lane provided editorial assistance, with funding from Bl.

\section{Author details}

'Department of Orthopaedics, Sahlgrenska University Hospital, SE 41345 Gothenburg, Sweden. ${ }^{2}$ Thrombosis Research Institute, Emmanuel Kaye Building, Manresa Road, London, UK. ${ }^{3}$ Innlandet Hospital Trust, Brumunddal, 
Norway. ${ }^{4}$ Department of Anaesthesiology and Intensive Care, Paris Descartes University, Cochin Hospital (AP HP), Paris, France. ${ }^{5}$ Corporate Department of Medical Affairs, Boehringer Ingelheim Pharma GmbH \& Co. KG, Ingelheim am Rhein, Germany. ${ }^{6}$ Center of Thrombosis, University Hospital Mainz, Mainz, Germany. ${ }^{7}$ Medical Data Services, Boehringer Ingelheim Pharma GmbH \& Co. KG, Ingelheim am Rhein, Germany. ${ }^{8}$ Department of Medicine, University of Heidelberg, Heidelberg, Germany. ${ }^{9}$ University of Texas Southwestern Medical Center, Dallas, TX, USA. ${ }^{10}$ Department of Orthopedics, Medical University of South Carolina, Charleston, SC, USA.

Received: 16 July 2015 Accepted: 6 August 2015

Published online: 17 November 2015

\section{References}

1. Eriksson BI, Dahl OE, Rosencher N, Kurth AA, van Dijk CN, Frostick SP, et al. Dabigatran etexilate versus enoxaparin for prevention of venous thromboembolism after total hip replacement: a randomised, double-blind, non-inferiority trial. Lancet. 2007;370:949-56.

2. Eriksson BI, Dahl OE, Huo MH, Kurth AA, Hantel S, Hermansson K, et al. Oral dabigatran versus enoxaparin for thromboprophylaxis after primary total hip arthroplasty (RE-NOVATE I*). A randomised, double-blind, non-inferiority trial. Thromb Haemost. 2011;105:721-9.

3. Eriksson Bl, Dahl OE, Buller HR, Hettiarachchi R, Rosencher $\mathrm{N}$, Bravo ML, et al. A new oral direct thrombin inhibitor, dabigatran etexilate, compared with enoxaparin for prevention of thromboembolic events following total hip or knee replacement: the BISTRO II randomized trial. J Thromb Haemost. 2005;3:103-11.

4. Friedman RJ, Dahl OE, Rosencher N, Caprini JA, Kurth AA, Francis CW, et al. Dabigatran versus enoxaparin for prevention of venous thromboembolism after hip or knee arthroplasty: a pooled analysis of three trials. Thromb Res. 2010;126:175-82.

5. Eriksson BI, Smith JJ, Caprini J, Hantel S, Clemens A, Feuring M, et al. Evaluation of the acute coronary syndrome safety profile of dabigatran etexilate in patients undergoing major orthopedic surgery: findings from four Phase 3 trials. Thromb Res. 2012;130:396-402.

6. The European Agency for the Evaluation of Medicinal Products. Guideline on clinical investigation of medicinal products for prophylaxis of high intra- and post-operative venous thromboembolic risk. CPMP/ EWP/707/98 Rev. 1. 2007. http://www.ema.europa.eu/docs/en_GB/ document_library/Scientific_guideline/2013/05/WC500143764.pdf. Accessed 30 June 2015.

7. The European Agency for the Evaluation of Medicinal Products. Points to consider on application with 1. meta-analyses; 2. one pivotal study. CPMP/EWP/ 2330/99. 2001. http://www.ema.europa.eu/docs/en_GB/document_library/Scien tific_guideline/2009/09/WC500003657.pdf. Accessed 30 June 2015.

8. Normand SL. Meta-analysis: formulating, evaluating, combining, and reporting. Stat Med. 1999;18:321-59.

9. Higgins JP, Thompson SG, Deeks JJ, Altman DG. Measuring inconsistency in meta-analyses. BMJ. 2003;327:557-60.

10. Eriksson BI, Borris LC, Friedman RJ, Haas S, Huisman MV, Kakkar AK, et al. Rivaroxaban versus enoxaparin for thromboprophylaxis after hip arthroplasty. N Engl J Med. 2008;358:2765-75.

11. Lassen MR, Gallus A, Raskob GE, Pineo G, Chen D, Ramirez LM. Apixaban versus enoxaparin for thromboprophylaxis after hip replacement. N Engl J Med. 2010;363:2487-98.

12. U.S. Food and Drug Administration. Guidance for Industry. Drug-Induced Liver Injury: Premarketing Clinical Evaluation. http://www.fda.gov/downloads/drugs/ guidancecomplianceregulatoryinformation/guidances/ucm174090.pdf. Accessed 30 June, 2015.

13. Geerts WH, Bergqvist D, Pineo GF, Heit JA, Samama CM, Lassen MR, et al. Prevention of venous thromboembolism: American College of Chest Physicians Evidence-Based Clinical Practice Guidelines (8th Edition). Chest. 2008;133:381S-453S.

14. Friedman RJ, Gallus AS, Cushner FD, FitzGerald G, Anderson Jr FA. Physician compliance with quidelines for deep-vein thrombosis prevention in total hip and knee arthroplasty. Curr Med Res Opin. 2008;24:87-97.

15. Wolowacz SE, Roskell NS, Maciver F, Beard SM, Robinson PA, Plumb JM, et al. Economic evaluation of dabigatran etexilate for the prevention of venous thromboembolism after total knee and hip replacement surgery. Clin Ther. 2009;31:194-212
16. Fernandes RA, Quintella FF, Teich VD. Cost-effectiveness analysis of dabigatran etexilate versus enoxaparin for the prevention of venous thromboembolism after total hip replacement under the Brazilian public health care system perspective [abstract]. Value Health. 2009;12(7):A502.

17. Boersma C, Kappelhoff BS, Postma MJ. Dabigatran etexilate is cost-saving for the primary prevention of venous thromboembolic events following major orthopaedic surgery in the Netherlands [abstract]. Value Health. 2009;12(7):A334.

\section{Submit your next manuscript to BioMed Central and take full advantage of:}

- Convenient online submission

- Thorough peer review

- No space constraints or color figure charges

- Immediate publication on acceptance

- Inclusion in PubMed, CAS, Scopus and Google Scholar

- Research which is freely available for redistribution 